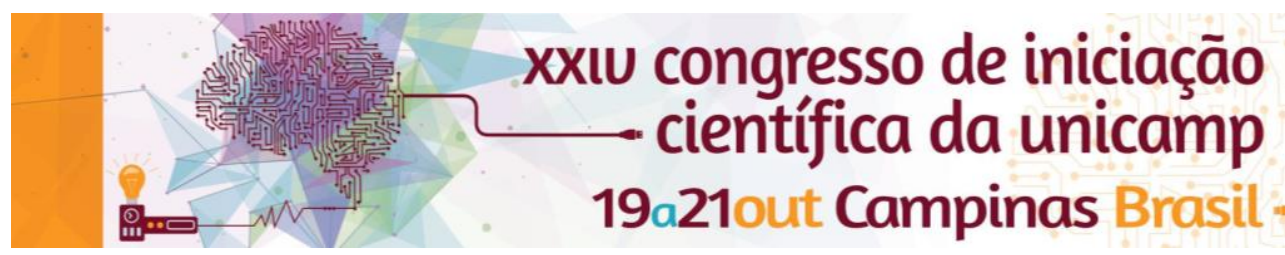

\title{
Determinação molecular de pacientes portadores de doença de von Willebrand.
}

\author{
Humberto V S Chaves*, Lúcia H Siqueira, Alessandra N Prezotti, Carolina Costa-Lima, Samuel S Medina, \\ Margareth C Ozelo.
}

\begin{abstract}
Resumo
A doença de von Willebrand (DVW) é o distúrbio hemorrágico hereditário mais comum, sendo causada por mutações no gene do fator de von Willebrand (FVW). A determinação do diagnóstico e subtipo correto é essencial para se estabelecer tratamento e aconselhamento genético adequados. Nesse estudo foram investigadas as mutações associadas ao diagnóstico de DVW em 34 pacientes, pertencentes a 17 famílias distintas. A partir do sequenciamento direto da região compreendida entre os éxons 18-28 do gene do FVW. Confirmamos a mutação em homozigose em dois pacientes não relacionados (p.R1341Q associado com DVW tipo 2B e p.R854Q associado com DVW tipo 2N). Além da provável mutação em heterozigose p.D1277G em 18 membros de uma mesma família com DVW tipo1.
\end{abstract}

\section{Palavras-chave}

Doença de von Willebrand, mutação, doença hemorrágica hereditária

\section{Introdução}

A doença de von Willebrand (DVW) é o distúrbio hemorrágico hereditário mais comum, sendo causada por mutações no gene do fator de von Willebrand (FVW) composto por 52 éxons. A determinação do diagnóstico e subtipo correto é essencial para o tratamento e aconselhamento genético adequados. Nesse estudo foram investigadas as mutações em 34 pacientes, pertencentes a 17 famílias distintas.

\section{Resultados e Discussão}

Foram selecionados 34 pacientes entre os 299 pacientes com DVW em seguimento no Hemocentro da Unicamp. Vinte e quatro pacientes pertencentes de sete famílias distintas apresentavam diagnóstico de DVW tipo 1 (alteração quantitativa de herança autossômica dominante) com fenótipo grave. Além de cinco indivíduos não relacionados com suspeita de DVW 2B (alteração funcional com frequente plaquetopenia associada) e cinco não relacionados com suspeita de DVW $2 \mathrm{~N}$ (disfunção da ligação entre FVW e fator VIII, herança autossômica recessiva). A partir do sequenciamento da região entre os éxons $18-28$ do FVW foi confirmada a mutação em 2 famílias, além de outra provável mutação. Uma das pacientes do sexo feminino foi encaminhada ao Hemocentro da Unicamp aos 23 anos com o diagnóstico de trombocitopenia autoimune (PTI) desde a infância. Na avaliação inicial, paciente encontrava-se gestante e apresentava plaquetopenia grave $\left(10 \times 10^{9} / \mathrm{L}\right)$ com resposta aumentada de agregação induzida à ristocetina (RIPA). O caso foi confirmado como DVW tipo 2B, tendo sido determinada a mutação p.R1341Q em homozigose. Um dos pacientes do sexo masculino com 66 anos e história de sangramento leve durante extração dentária. $\mathrm{Na}$ avaliação laboratorial apresentava níveis de fator VIII entre $25-73 \%$ (VR: $50-150 \%$ ) e demais exames normais. Foi descartado diagnóstico de hemofilia $A$ e na avaliação determinada a presença da mutação em homozigose p.R854Q confirmando o diagnóstico de DVW tipo $2 \mathrm{~N}$. Uma das famílias investigadas constituída por 18 indivíduos com história hemorrágica grave e apresentando antígeno de FVW (FVW:Ag) entre 5-20 Ul/dL (VR: 44-180), cofator de ristocetina (RiCof) 4-13\% (VR: 50-180). Na investigação foi observado uma provável mutação em heterozigose p.D1277G.
Os dados laboratoriais dos casos índices investigados estão resumidos na tabela.

Tabela 1. Dados laboratorias dos casos índices investigados.

\begin{tabular}{|l|c|c|c|c|c|c|}
\hline ID & Fam & FVW:Ag & RiCof & FVIII & DVW & Mutação \\
\hline RF & 1 & 14 & 4,3 & 10,2 & Tipo 1 & p.D1277G \\
\hline AL & 2 & 11 & 10,6 & 31,6 & Tipo 1 & - \\
\hline MT & 3 & 12 & 9,8 & 20 & Tipo 1 & - \\
\hline MD & 4 & 4 & 4 & 4,3 & Tipo 1 & - \\
\hline VA & 5 & 6 & 10 & 20 & Tipo 1 & - \\
\hline JS & 6 & 15 & 6,9 & 19,5 & Tipo 1 & - \\
\hline HS & 7 & 55 & 30 & 45 & Tipo 1 & - \\
\hline GR & 8 & 483 & 48,2 & 247 & Tipo 2B & p.R1341Q \\
\hline ES & 9 & 113 & 106,5 & 108 & Tipo 2B & - \\
\hline LA & 10 & 98 & 103 & 76,6 & Tipo 2B & - \\
\hline MS & 11 & 159 & 100 & 182 & Tipo 2B & - \\
\hline MB & 12 & 103 & 97 & 99 & Tipo 2B & - \\
\hline IC & 13 & 127 & 135 & 25,3 & Tipo 2N & p.R854Q \\
\hline AS & 14 & 35 & 31,5 & 4,6 & Tipo 2N & - \\
\hline AV & 15 & 72 & 47,7 & 27,1 & Tipo 2N & - \\
\hline MRS & 16 & 87 & 150 & 14,2 & Tipo 2N & - \\
\hline VR & 17 & 64 & 91,6 & 23,5 & Tipo 2N & - \\
\hline & & & & & & \\
\hline
\end{tabular}

\section{Conclusões}

Nesse estudo foram investigadas as mutações associadas à DVW em 17 famílias distintas, tendo sido confirmado o diagnóstico molecular em duas além de uma provável mutação. Todos os demais casos investigados apresentavam diversas alterações na região do FVW estudada que correspondem à diversos polimorfimos. Este fato reforça a característica polimórfica do $F V W$ e explica a dificuldade na determinação da mutação responsável da DVW.

\section{Agradecimentos}

Conselho Nacional de Desenvolvimento Científico e Tecnológico(CNPq). 